Cross-Level Investigation of Team \& Individual Job Crafting

\title{
A Cross-Level Investigation of Team-member Exchange on Team and Individual Job Crafting with the Moderating Effect of Regulatory Focus
}

\begin{abstract}
This study examined, within the framework of regulatory focus theory, the affecting causes of individual job crafting, team-member exchange relationships, influence of team job crafting on individual job crafting, and the cross-level moderating effect of regulatory focus. Purposive sampling was adopted by this researcher as a means to collect data. A total of 123 teams with 514 members were invited to participate in the survey, of which 91 teams with 354 members provided valid questionnaire responses for data analysis. Mplus 7.0 was applied to conduct data analysis and verification. Data analysis demonstrates that (1) TMX exerts positive influence on team job crafting and individual job crafting; (2) team job crafting positively affects individual job crafting; (3) TMX can positively affect individual job crafting via team job crafting; (4) a prevention focus has a moderated mediation effect on the indirect relationship between TMX and individual job crafting.

This study has both practical and theoretical implications, based on the findings. This research applied cross-level investigation of individual job crafting, coupled with human relationships and prediction of the causes of individual job crafting. It can be regarded as a pioneering academic endeavor. Practically, this study can be referred to an organization. It can enhance teamwork, postulate job flow, and promote the quality of member relationships, thus boosting individual job crafting performance.
\end{abstract}

Keywords: team-member exchange; team job crafting; individual job crafting; regulatory focus 


\section{A Cross-Level Investigation of Team-member Exchange on Team and Individual Job Crafting with the Moderating Effect of Regulatory Focus}

Organizational study in the past few years has been found to place increasing emphasis on job crafting. It has been frequently pointed out that employees' jobcrafting can positively influence the individuals (employees) and the team, including enhancing personal (employee) job satisfaction, commitment and performance and reducing turnover rate (Bakker, Rodríguez-Muñoz \& Sanz-Vergel, 2012; Petrou, Demerouti \& Peeters, 2012; Tims, Bakker \& Derks, 2013). Obviously, employees' job crafting not only benefits their job performance but also satisfies an organization's expectations of their job behavior. Past studies, however, have tended to focus on prediction of employees' job performance and to neglect the causes and ways that motivate individual job crafting (Berg, Dutton, \& Wrzesniewski, 2013). This little-tackled area, therefore, needs more academic endeavor. It is one of the motivations of this study to understand the causes accounting for employees' job crafting.

Job-crafting studies have tended to be concerned with employees. Recently, however, more emphasis has been placed on team job crafting (Leana, Appelbaum, $\&$ Shevchuk, 2009; McClelland, Leach, Clegg, \& McGowan, 2014; Tims et al., 2013). A team is, practically, a basic unit meant for completing a job (Vaskova, 2007). For this reason, Wrzesniewski and Dutton (2001) regarded it as necessary to study team job crafting. Related studies on team job crafting show that it can positively affect team job satisfaction and commitment (Leana et al., 2009), and job engagement and performance (McClelland et al., 2014; Tims et al., 2013). Nevertheless, little knowledge exists about the causes of team job crafting. Berg et al. (2013) emphasized the importance of both interpersonal relationships between team members and 
personal influence. Cross-level influence, therefore, deserves more attention (Salas, Shuffler, Thayer, Bedwell, \& Lazzara, 2015). An understanding of the causes of team job crafting, therefore, is the second motivation of this study.

Employees' organizational behavior is subject to environmental influences. Team members' influence, no doubt, is the most direct (Hoegl, Parboteea, \& Gemuenden, 2003). A recent study on social community, teamwork and social resources has suggested interpersonal relationships among coworkers can lead to meaningful results (Dachner \& Miguel, 2015), such as knowledge sharing (Yang et al., 2011) and organizational civil behavior (Farmer, Linn, \& Dishan, 2015). The theoretical model of job crafting, according to past studies, needs to take social factors in a work environment into consideration, particularly coworkers and teamwork (Bakker et al., 2016). In view of this, this research investigated whether the quality of member relationships influences the team and individual job crafting by referring to member relationship as the preceding variable of prediction of team and individual job crafting.

Brass and Burkhardt (1993) pointed out that employees' interests and personality traits account for their use of a social community. According to their study, personal initiative and a proactive personality are related to individual job crafting. Employees with those two personality traits can exhibit higher job crafting behavior (Bakker, Tims \& Derks, 2012; Tims \& Bakker, 2010). However, this can only predict the degree of individual job crafting; it does not explain whether differences in personally traits have a moderating effect on job crafting. Higgins (1997) distinguished "promotion focus" from "prevention focus". Members with different inner needs and cognitive styles are likely to implement different strategies and following behaviors. This study investigated whether members with different 
regulatory focus traits interfere with the relationships of team-member exchange and the indirect relationship of individual job crafting and whether different traits exert influence on personal behavior.

This study was expected to have three contributions. First, by investigating the influence of team-member exchange relations on team job-crafting and individual job crafting, it fully explained the influence of human relations and social connection on job crafting. Therefore, it filled an academic area little dealt with before. Second, it investigated the mediating effect of team job crafting, that is, whether the quality of team interaction can affect individual job crafting through team job crafting. Third, it further investigated how the personal regulatory focus trait interferes with the above-mentioned relationships, that is, whether the personal personality trait enhances or reduces the influence of the team scenario on personal behavior.

\section{Relationship between Team-member exchange and Individual Job crafting}

According to social cognitive theory, the processing of human beings is based on a mutual influence between the individual, behavior and environment. Bandura (1986) reported that personal cognition plays a key role in fact construction, self-regulation, coding information and behavior manifestation. As a result, during the team member interactions, some members' verbal and behavioral transmissions of their perspectives about a specific event/incident may change other team members' behavior and attitude (Seers, 1998). The interactions between members can help them construct job contents, such as job characteristics, job type and job-performing method. All these can not only help define the job model and postulate a mission's domain (Wrzesniewski \& Dutton, 2001), but they can also further create job identity. In addition, high-quality team-member exchange relationships allow members to fully 
interact with each other and freely express their thoughts. Members can be evaluated by other members as to their ability, job value and job role.

Interpersonal interactive behavior is, in terms of resources, a process in which participants are engaged in an activity relevant to them. They possess and exchange valuable resources (Homans, 1958). Supervisors and coworkers may provide useful feedback and resources, and their discussions about job competition are very likely to affect other workers' learning and innovation. It can also make a mission more challenging and diversified, thus elevating the degree of job crafting (Leana et al., 2009; Yang, 2012). According to this study, team members can not only help other members understand their job role and mission content, but they can also transmit their perspectives about the job and provide sufficient resource by means of communication and interflow. This enables members to have more opportunity and ability to undergo individual job crafting, suggesting the hypothesis:

H1: Team-member exchange relationships can positively affect individual job crafting.

\section{Team-member exchange Relationships and Team Job-crafting Relationships}

On-the-job interpersonal relationships, which extend and develop with social interaction and mission interaction time, are the basis of group activity (Weick, 1979). According to the concept of group activity in social cognitive theory, when a group shares collective power (force), they can turn out a common belief and possess the same mission objective. Team members have a group-identified direction and convert personal interest into group interest and work together for an expected goal (Brewer \& Gardner, 1996). In addition, in order to accomplish the same mission, members not only need commonly shared knowledge and skill but also must communicate and 
work together through interaction and effective communication to generate effective outputs (Bandura, 2000). Individuals tend to work with those better associated with themselves (Dachner et al., 2015). Obviously, with the quality of member interactions becoming higher, team members can freely express their own thought and share others' knowledge and skill, thus enabling them to have common beliefs about collective efficacy and expected outcomes. They define job flow, jointly create job resources and job requirements, and enhance team job crafting to achieve common objectives (Tims et al., 2013).

Empirical studies in past years have also suggested that social connections and interactive relationships between teachers and their assistants can positively affect cooperative job crafting, change the job environment and the job performing method, and eventually uplift care quality (Leana et al., 2009). Therefore, this study suggested that good relational quality can provide team members with more knowledge sharing and feedback. With more resource and confidence, they can together determine an appropriate job method. They can, through effective communication and interflow, create a more suitable job environment for the team, share job resources, meet the job's needs and, eventually, realize a common objective. They can be expected to work together to model a mission and a practical job (Ghitulescu, 2006). Thus the hypothesis:

H2: Team-member exchange relationships can positively affect team job crafting.

\section{The Relationship between Team Job crafting and Individual Job crafting}

Team job members can influence one another. Some team members' emotions and behaviors can affect others' personal emotions and behaviors (Torrente, Salanova, Llorens \& Schaufeli, 2012). According to group rule and social cognition theory, 
group rule defines personal behavior. The individuals display actual behavior by imitating others. The group rule dictates members' common belief about expected behavior, which can guide personal behavior (Carron \& Hausenblas, 1998; Taggar \& Ellis, 2007). If a team can build up a common mission, rule, behavioral mode and interaction relationships in a short time, members can have something to refer to or rely on (Abelson, 1976). Group rule is quite influential. Conforming to a group rule can likely cause members to feel stressed to a certain degree (Barker, 1993). Therefore, when a group rule is applied to what happens to the group, it is sure to affect the individual members. If members solve a group problem proactively, team job crafting will then send out a signal to urge the individual members to actively change job characteristics.

Individual members in these groups develop knowledge of the group rule through observing other members' behaviors and responses (Postmes, Spears, \& Lea, 2000) and are more likely to participate in other members' job crafting. Members can judge which behavior is fitting for a certain work scenario. They must take into consideration job characteristics, including similarity, status and success, so they can judge whether the behavior is worth imitating and whether it can lead to a valuable result. Thus, we have the following hypothesis.

H3: Team job crafting can positively affect individual job crafting.

\section{The Mediating Effect of Team Job crafting}

Social relations provide members' actions with direction and create safe environments through knowledge sharing and group members' changes (Caldwell \& O'Reilly, 2003; Edmondson, 1999). As a result, the higher the quality the team members' interactions become, the more knowledge sharing, resource interflowing 
are inspired. Members accomplish a common objective by defining the job objective and job flow, collectively creating job resources, satisfying job needs, and strengthening job crafting among the members (Tims et al., 2013).

In addition, the members' interactive process can exhibit a collective sense of efficacy (Bandura, 2001). With provision of new resources and changing of job environments, employees can engage themselves in the social learning process by following group beliefs and common beliefs (Cannon-Bowers \& Salas, 2001). Members do not have to experience or try errors. Rather, they can learn new behavior through observing others' behavior (Bandura, 2001). Therefore, once team members share the job experience and complete a mission, they can create a propaganda effect. Coworkers help them improve the job environment and add to their personal environmental adjustment (Bakker et al., 2016; Tims \& Bakker, 2010). Team members can motivate others to complete their personal mission. For example, when team members believe they alone can carry out and complete a mission, individual members can not only imitate them but become more confident in performing their own role. Team members' self-expectations can be obtained through providing more social resources or making a job mission more challenging (Tims et al., 2013). A study conducted domestically pointed out that job modelers share with each other what they gain from the job, learn skills acquired by others and improve their own skills and interpersonal relations, and redefine their own job identity (Wu, 2009).

This study, therefore, suggested that high quality relationships help members share knowledge and resources with each other and jointly change their job environments. They jointly define job flows, job objectives and job methods. They obtain more job and relationship resources to balance job needs and, consequently, complete the mission. The individuals observe and learn such value-based behavior as 
is exhibited by other members (Bandura, 1986). This helps them define their role, develop effective beliefs and change their perspectives about their job and job method (Leana et al., 2009). Then, we have the suggesting hypothesis.

H4: Team-member exchange relationships, which positively affect individual job crafting, can regulate a moderated mediating effect through team modeling behavior.

In addition to discussing mediating effects and moderation effects, Baron and Kenny (1986) also discussed the combined effect of both, that is, moderated mediation and mediated moderation. By moderated mediation effect is meant that any path (direct effect, indirect effect or combination of both) can be influenced by another moderation variable (Edeard \& Lambert, 2007; Muller, Tudd, \& Tzerbyt, 2005). Leana et al. (2009) suggested that larger job environments and job characteristics can motivate employees' job behaviors. An employee's conception of the job environment, job characteristics (personality trait, for instance) and personal preference for and orientation toward a job (motivation for achievement, for instance) affects the employee's job-crafting occurrence rate and intensity. Additionally, an employee can simultaneously take part in personal and cooperative job crafting. This means there are still other influential moderation causes pertaining to a job environment.

Wrzesniewski and Dutton (2001) pointed out, on the basis of the job-crafting model; the motivation for job crafting can satisfy the needs of job achievement. It can change job action and meaning by enhancing one's sense of the job objective. In addition, a close combination of personal factors and job objectives will strengthen each other's role. A past study has also suggested that employees with personal initiative and a proactive personality can display higher job crafting (Tims \& Bakker, 
2010; Tims et al., 2012). This implies that personality traits and motivation can interfere with an environment regarding its influence on personal behavior.

According to the regulatory concept proposed by Higgins (1997), people with different personality traits may adopt different strategies owing to different needs. People with a promotion focus care more about whether there is an opportunity for growth and progress. They search for an expected objective, and they also actively adopt a less distant objective strategy for a good result. People with prevention focus, on the contrary, place more emphasis on personal security and assurance and are very sensitive to loss of resources. When searching for an objective, they tend to rely on personal self-conscious obligation, duty and responsibility. They work with deliberation and caution and try their best to prevent making mistakes (Brockner et al., 2004; Crowe \& Higgins, 1997; Liberman et al., 2005). In other words, someone's personal cognition ability dictates their following behavior. It makes an individual employee understand what objective to achieve and the amount of effort to spend (Bandura, 1986). Past empirical research indicates that people with different a regulatory focus respond and behave differently to the same event/incidence, such as group-decision behavior (Levine et al., 2000), as a result of different cognitive styles. It can be expected, therefore, that people with a different regulatory focus will also adopt different behaviors and strategies when faced with environmental influences. Two different strategies are meant to either allow individuals to access the expected status (promotion focus) or help individuals avoid an expected dilemma (prevention focus) (Crowe \& Higgins, 1997).

Hypothesis 4 points out that the quality of team relationships can affect personal emotions and behaviors. Through in-group interactions, team members can, by following the team's collective belief and common experiences, contribute new job 
resources and change the job environment (Cannon-Bowers \& Salas, 2001). Social relationships can present individuals a direction to follow. When performing a job, employees can imitate and follow other members' outwardly valuable behaviors (Bandura, 1986). They will then be able to judge the appropriateness of behaviors by observing what others do.

Therefore, those who fall into the prevention focus category will follow the situational clues manifested by social relationships for the sake of their security needs. When performing a job, they tend to exhibit safe behavior, which can be reproduced or imitated. When they make a decision, they will view the team objective and interests as a major concern. They are sensitive to negative outcomes and loss of resources. Hsu et al (2015) suggested that people with a prevention focus are likely to feel stressed when making a suggestion and will eventually become psychologically exhausted. They prefer to maintain the status quo to prevent unwanted event/incidents from occurring. They are careful about decision making so as to avoid making mistakes (Keller, 2006). They follow the team rule and adjust personal behavior by referring to the overall job crafting. In contrast, those with a promotion focus are more willing to take and assume risks to enhance opportunities to complete their objective (Keller, 2006). Consequently, the situational clues and resources provided by social relationships become merely one way to access an objective and not the only way to accomplish the objective. If in-group interaction quality and team job crafting frequencies are low, these employees may not necessarily be influenced by the team's scenario. Instead, they use their own way to search for personal growth and achievement by actively approaching the objective (Keller, 2006). H5: Regulatory focus can moderate the indirect relationship between the team-member exchange relationships and individual job crafting. Those with a 
prevention focus can enhance the indirect relationship between team-member exchange relationships and individual job crafting. Those with a high-promotion focus are less likely to display a moderating effect.

\section{Methodology}

\section{Sampling and Procedure}

This study is originated from a project of MOST (Ministry of Science and Technology, Taiwan) regarding job crafting. The project has been sent to the Ethics Committee of NCUE (National ChangHua University of Education, Taiwan) approved to do sampling and purposive sampling was employed to recruit participants. Participants have to be informed consent. The questionnaires were distributed to 123 teams and each team contains 2 to 4 persons. Each team comprised at least three team members. Every team member has been in his or her position no less than three months. Every team member must have a common goal, similar job duties, and work responsibilities. For teams with more than six members, there more than half of the team members should have returned their inventories to be counted as a valid team. Finally, there were 108 teams, with 442 members returning their questionnaires. The response rate was $87.8 \%$. Deleting invalid returned questionnaires resulted in 91 teams (or 364 valid questionnaires). The effective return rate was $84.2 \%$. Among all participants, $65.1 \%$ were women; $26.1 \%$ participants were older than 41 years old, while $25.5 \%$ were aged between 26 and 30. Seventy-two percent (72\%) of the participants had completed college or a graduate degree. Twenty-nine point four participants have one to three years of working experience, while $21.7 \%$ of participants have over 10 years of working experiences. As to team size, most teams comprise 6-10 team members $(41.5 \%)$. 
Data were collected in two waves. For the first wave, participants were requested to fill in "team-member exchange" and "team job crafting" questionnaires and some demographic information that could be used as identification labels. The second wave questionnaires were distributed to the same participants one month after they returned their first wave questionnaires. The second wave questionnaires including "regulatory focus" and "individual job crafting" and some demographic information that could be used to identify the participants. The returned questionnaires' data for two waves would be analyzed by dyad method. Figure 1 shows the research framework.

\section{Insert Figure 1 here}

\section{Instruments}

Team-member exchange. The team-member exchange questionnaires were adopted from part of Seers'(1989) work to measure interaction relationships among colleagues. The instrument comprises 10 items. The Cronbach's $\alpha$ is .76. Confirmatory factor analysis yielded construct reliability of .77 with .27 AVE. Although AVE may not achieve a satisfactory level, Fornell and Lacker (1981) indicated that a scale with good construct reliability could be regard as possessing good convergence validity

Individual job crafting. The 21-item individual job-crafting scale (Tim et al, 2012) was used to measure individual job crafting. The Cronbach's $\alpha$ was .95. Confirmatory factor analysis indicated that construct reliability was .81; AVE was .53.

Team job crafting. The 21 -item job crafting scale (Tim et al., 2012) modified some wordings to fit the usage of a team job-crafting measure. The Cronbach's $\alpha$ 
was .90 . The construct reliability was .84 and AVE was .58.

Regulatory focus. An 18-item, 5-point Likert scale(Lockwood, Jordan, \& Kunda, 2002) was used to measure regulatory focus. The Cronbach's $\alpha$ for facilitating and prevention regulatory focus were .86 and .82 , respectively. Construct reliability were .87 and .83 , respectively. AVE for facilitating and prevention regulatory focus were .43 and .33 .

Control variable. According to the literature review, educational backgrounds (Tims et al., 2010) and work experiences (Niessen, Weseler, \& Kostova, 2016 ) were both served as control variables.

\section{Aggregation of Group Level Data}

This study examined Rwg and ICC(1), ICC(2) for group level variable "team member exchange" and "team job crafting". The Rwg for team-member exchange ranged from .83 to 1.00 with mean value .92 , while Rwg for team job crafting fell to between .80 to .98 with mean value .90 , which was indicating that the RWG value is reasonable. For between group variance, the ICC(1) between team-member exchange and team job crafting were 0.11 and 0.25 ; $\operatorname{ICC}(2)$ were 0.34 and 0.56 . ANOVA analysis showed that there were group differences between team-member exchange and team job crafting.

\section{Overall Model Fit}

The overall model fit indices were as follows: $\chi^{2} / \mathrm{df}$ is 2.40 ; GFI is 0.70 ; CFI is 0.92; NNFI is 0.87 ; RMSEA is 0.06 . Other than the GFI value, the rest values are acceptable. This indicated that the research model is still acceptable.

\section{Results}




\section{Common Method Variance}

To ensure the results did not suffer from the problem of common method variance (CMV), Harman's one-factor test was employed to reveal that the variance accountable for the first factor was only $19.82 \%$. Additionally, cross-level study is a way to reduce common method variance, this approach is called unit isolation analysis (Podsakfoff et al.,2003).

\section{Correlational Analysis among Study Variables}

Table 1 shows that Pearson's $r$ indicated that bivariate correlation between every pair of variables except the pair of team-member exchange relationships and prevention focus. Moreover, the largest Pearson's correlation coefficient was 0.56 , which meant low collinearity threats among these variables.

\section{Insert Table 1 here}

\section{Team-member Exchange Relationships, Team Job crafting and Individual Job crafting}

In order to realize the relationships among the study variables, Multilevel Modeling was employed to analyze the direct effect of team-member exchange on team and individual job crafting and the mediating effect of team job crafting between team-member exchange and individual job crafting.

Table 2 shows the relationships among team-member exchange, team and individual job crafting. In model 1 , team-member exchange positively predicted individual job crafting $(\beta=.49, p<.001)$; in model 2 , team -member exchange positively predicted team job crafting $(\beta=.65, p<.001)$. This indicated that the higher the interaction quality of team members, the higher both the team and individual job 
crafting; thus, hypothesis 1 and hypothesis 2 were validated. In model 3, team job crafting also positively predicted individual job crafting $(\beta=.54, p<.001)$; hypothesis 3 was supported. In model 4 , when both team-member exchange and team job crafting were entered for analysis, the $\beta$ value decreased from $.55(p<.001)$ to .16 ( $p>.05)$. Team job crafting still positively predicted individual job crafting $(\beta=.47$, $p<.001)$; the indirect relationships was $.30(p<.001)$. Team job crafting was fully mediating the relationship between team-member exchange and individual job crafting. Thus, team level team-member exchange could influence team job crafting and, in turn, influence individual job crafting. Hypothesis 4 was supported.

\section{Insert Table 2 here}

Insert Table 3 here

\section{The moderating effect of prevention regulatory focus}

Table 4 shows the prevention regulatory focus. Team-member exchange positively predicted team job crafting ( $(\beta=.646, \mathrm{p}<.001)$. The interaction of intergroup team-member exchange reached the marginal significance level $(\beta=.047, \mathrm{p}$ $=.069<.1)$; this indicated that prevention regulatory focus still moderated the indirect relationship between team-member exchange and individual job crafting. The moderating effect of prevention regulatory focus was shown in Figure 1.

Figure 2 shows that when individual prevention focus is low (-1.0 SD), 95\% confidence interval of indirect effect fell between .067 and .350 . When individual 
prevention focus is high $(+1.0 S D), 95 \%$ confidence interval of indirect effect fell between .157 and .559 . When individual prevention regulatory focus raised to $2.0 S D$ above the mean, $95 \%$ confidence interval of indirect effect fell between .160 and .705 , 0 was still excluded. When individual prevention focus was $-2.0 S D$ below the mean, $95 \%$ confidence interval of indirect effect fell between -.050 and .317 , indicating that with the increase of prevention regulatory focus, the indirect effect of team-member exchange and individual job crafting will become higher.

\section{Insert Figure 2 here}

Insert Table 4 here

\section{Moderating Effects Differences Using Invariant Analysis}

The invariant analysis was used to reveal the differences between individuals with prevention regulatory focus and promotion regulatory focus that would lead to discrepant moderating effects on the indirect relationships of team-member exchange and individual job crafting.

Table 5 shows the results. The $\beta$ value for high prevention regulatory focus was $.663(\mathrm{p}<.05), S D$ was .123 ; this study regarded these values as $\beta_{1}$ and $S e \beta_{1}$. The $\beta$ value for high-promotion regulatory focus was .068(n.s.), $S D$ was .177; this study regarded these values as $\beta_{2}$ and $S e \beta_{2 . .}$. Then, both $\beta_{1}$ and $S e \beta_{1}$ as well as $\beta_{2}$ and $S e \beta_{2}$. were applied to the following formula in Figure 3: the discrepancy between high-promotion regulatory focus and high prevention regulatory focus was 2.76 , which exceeded the 
standard normal $t$ distribution critical value(1.645). This implied that a difference exists between high-promotion regulatory focus individuals and high prevention individuals. Regulatory focus moderated the indirect relationships between team-member regulatory focus and individual job crafting. Hypothesis 5 was supported.

Insert Figure 3 here

\section{Insert Table 5 here}

\section{Conclusion and Discussion}

Some conclusions were obtained after the study. Firstly, team-member exchange positively predicted individual job crafting and team job crafting, respectively. The higher the team-member exchange, the higher the team job crafting and individual job crafting. Secondly, team job crafting positively predicted individual job crafting. The higher team job crafting is, then the higher individual job crafting is. Thirdly, team job crafting fully mediated the relationships between team-member exchange and individual job crafting. Fourthly, prevention regulatory focus moderated the relationship between team-member exchange and individual job crafting. The invariant analysis indicated the relationships between team-member exchange and individual job crafting were different owing to individual personality traits. Individuals with high prevention focus compared to individuals with high-promotion focus were more likely to increase team-member exchange to influence the relationships between team job crafting and individual job crafting. 


\section{Academic Contribution}

Three major academic contributions resulted from this study. Firstly, this study strengthens the academic connection between individual and team level job crafting, which were not fully comprehended in the previous studies. According to these study results, when team members' interaction quality increased, individuals' job crafting frequencies would be higher. This finding echoed the study results of Leana et al. (2009). However, our study explored the cross-level relationships suggesting team level members' interaction quality could positively predict individual job-crafting frequency, filling the previous research gaps of only individual-level studies. By the way, this study not only revealed the possible precursors of individual job crafting (Wrzesniewski \& Dutton, 2013), but it also expanded to discover possible antecedents of team job crafting via validating the connections of quality team members' interaction and team job crafting (Berg et al., 2013).

Secondly, this study revealed the relationships between team-member exchange and individual job crafting. Furthermore, this study found team-member job crafting mediating the relationships between team-member exchange and individual job crafting.

Thirdly, this study is in response to the call that included TMX or team-member job crafting and individual factors, such as regulatory focus, to predict individual job crafting (Berg et al., 2013; Bakker et al., 2016). Individuals with a high-prevention regulatory focus were more likely to enhance the indirect relationships of TMX on individual job crafting than those with a high-promotion regulatory focus. This was owing to individuals with high-prevention focus tended taking more conservative measures than their colleagues to prevent resource losses, such as destroying interpersonal relationships, causing emotional exhaustion, and increasing work stress 
and so forth (Higgins, 1997). As to their decision-making processes, they were more likely to rely on team job crafting instead of individual job crafting. This behavior type was similar to Chinese cultural expectations that were in favor of collectivism to eliminate some unnecessary interpersonal problems.

\section{Management Implications}

Firstly, promoting quality team member interaction was necessary. Teammembers interaction was beneficial to individual job crafting. Thus, team or organizational leaders should set up opportunities that could increase members' interaction, such as collaborating on a single project. Some platforms could also serve as opinion- and knowledge-sharing points for team leaders and their subordinates to elicit more job crafting, working toward a common goal. In that sense, when a common goal was achieved, it was more likely to increase the sense of mutual trust and work efficacy.

Secondly, this study showed that team job crafting promoted individual job crafting; thus, an organization could increase opportunities for teamwork cooperation and let team members collaborate on work flow and guidelines, set common goals, and, in turn, establish a positive organizational climate. Conversely, when all colleagues work together to collaborate on their workflow and guidelines, that would make them feel empowered to be responsible for their work and for meeting their role expectations granted by the team.

Nevertheless, social norms were very important when conducting team job crafting. According to social cognitive theory, various learning effects will apply to the team members as future action guidelines (Bandura, 1997, p86). Thus, at the emergent stage of team formation, it was important to establish a role model. On the contrary, however, each newcomer could also be assigned an experienced colleague as 
a mentor to coach them on everything about the team or organization, including actively showing how to conduct work tasks, thinking styles, acquiring effective skills, environmental management and so forth.

Thirdly, effective management of individuals with a different regulatory focus is important. The organization should modify their management measures in accordance with their regulatory focus profiles; for example, prevention regulatory focus individuals, for the sake of safety, were more likely tuning their job crafting in reference to environmental or other circumstantial cues. Conversely, if the environment influences were not salient, these prevention regulatory individuals may not perform as the organization expected. Thus, group leaders could borrow from positive group power concepts to clearly explain what the organizational expectations are and let them know that detrimental loss may come across if they fail to achieve organizational expectations. As to high-promotion regulatory individuals, the supervisor should pay more attention to revealing whether or not their subordinates' work styles meet the organization's needs and expectations, or assign them tasks that did not interfere with other colleagues.

From viewpoints of a member in an organization, prevention regulatory focus individuals should put more environmental elements into consideration, including team job-crafting behavior frequency, organizational climates and so forth, to further examine whether these elements fitting to individuals' need and helpful in resources seeking to craft their jobs to meet individual personality traits, capacity and enthusiastic.

\section{Limitations of this study}

This study's limitations are mostly inherited from the methodology, although we tried to prevent them from happening. Firstly, self-report inventory reports are, 
inevitably, partially influenced by social expectations; for example, when team members were asked about their interpersonal relationships, they tended to give a more conservative reply when the answer was on the negative side so as to maintain their good impression in the team. We hid the participants' demographic identification information and psychological constructs information for the inventory items to prevent such answers (Butts et al., 2006). However, future studies can also add social expectation elements to the instruments to serve as a control variable. Secondly, owing to some sampling restrictions, the participant recruiting processes could not be fully random, so sampling error might not be eliminated. Thirdly, this study used a two-stage data collection process; however, many factors may intervene to influence participants' job crafting, which make it was challenging to make causal conclusions of job crafting change. Fourthly, most instruments were derived from studies from other countries; although we did our best to prevent biases caused by cultural differences, some tiny problems may, de facto, still exist. These should not influence the study results as a whole, but we must still be cautious.

\section{Suggestions for future studies}

According to the study results, it is possible for us to explore the causal relationships between team-member job crafting and individual job crafting. Previous literature had illustrated that team and individual job crafting were not mutually exclusive (Leana et al., 2009). Thus, this study merely tried to explore how team job crafting influences individual job crafting; however, it was known that an individual's behavior could be interactively influenced by personal, environmental and behavior factors. It was also possible for individual job crafting to affect team job crafting. Some dyad studies ( e.g., Bakker et al., 2016) indicated that individual job crafting affected team job crafting; nevertheless, they did not probe the fluid type of job 
crafting within a team by means of team-based, cross-level viewpoints. More researchers could use qualitative or longitudinal inquiry methods and multi-stage, self-report inventories to reveal job crafting fluidity within a team in the future.

There are several job-crafting viewpoints. This study used the four types of job-crafting aspects (Tims et al., 2010), including increasing work resources, increasing interpersonal resources, increasing challenging work demands, and decreasing obstacle work demands. Our study regarded these four as a whole job crafting concept; accordingly, we did not differentiate their effects. Future studies could be done to reveal whether team circumstance differences lead to promoting or preventing a particular type of job crafting. 


\section{References}

Abelson, R. P. (1976). Script processing in attitude formation and decision making. In J.S. Carroll \& W. J. Payne (Eds.), Cognition and Social Behavior. Hillside, NJ: Lawrence Erlbaum, pp.139-181.

Dachner, A. M., Miguel, R. (2015). Job crafting: an unexplored benefit of friendships in project teams. SAM Advanced Management Journal, 80(2), 13-21.

Bakker, A. B., Tims, M. \& Derks, D. (2012). Proactive personality and job performance: The role of job crafting and work engagement. Human Relations, 65(10),1359-1378.

Bakker, A.B, Rodríguez-Muñoz, A, \& Sanz-Vergel, A.I. (2016). Modelling job crafting behaviours: Implications for work engagement. Human Relations, 69(1),169-189.

Bandura, A. (1986). Social foundations of thought and action: A social cognitive theory. Englewood Cliffs, NJ: Prentice Hall.

Bandura, A. (1997). Self-efficacy: The exercise of control. New York: Freeman.

Bandura, A. (2000). Exercise of human agency through collective efficacy. Current Directions in Psychological Science, 9, 75-78.

Bandura, A. (2001). Social cognitive theory: An agentive perspective. Annual Review of Psychology, 52, 1-26.

Barker, J. R. (1993). Tightening the iron cage: Concertive control in self-managing teams. Administrative Science Quarterly, 38, 408-437.

Berg, J. M., Dutton, J. E., \& Wrzesniewski, A. (2013). Job crafting and meaningful work. In B. J. Dik, Z. S. Byrne \& M. F. Steger (Eds.), Purpose and meaning in the workplace (pp. 81-104). Washington, DC: American Psychological Association.

Brass, D. J., \& Burkhardt, M. E. (1993). Potential power and power use: An investigation of structure and behavior. Academy of Management Journal, 36(3), 441-470.

Brewer, M. B., \& Gardner, W. (1996). Who is the "we"? Levels of collective identity and self-representations. Journal of Personality and Social Psychology, 71, 83-93.

Brockner, J., Higgins, E. T., \& Low, M. B. (2004). Regulatory focus theory and the entrepreneurial process. Journal of Business Venturing, 19, 203-220.

Butts, M. M., Vandenberg, R. J., \& Williams, L. J. (2006). Investigating Susceptibility of Measurement Invariance Tests: The Effects of Common Method Variance. Proceeding of the Annual Meeting of the Academy of Management, Atlanta, GA.

Caldwell, D. F., \& O'Reilly, C. A. (2003). The determinants of team-based innovation in organizations: The role of social influence. Small Group Research, 34, 
497-517.

Cannon-Bowers, J. A., \& Salas, E. (2001). Reflections on shared cognition. Journal of Organizational Behavior, 22, 195-202.

Carron, A. V., \& Hausenblas, H. A. (1998). Group dynamics in sport (2 ${ }^{\text {nd }}$ ed.). Morgantown, WV: Fitness Information Technology Inc.

Crowe, E., \& Higgins, E. T. (1997). Regulatory Focus and Strategic Inclinations: Promotion and Prevention in Decision-making. Organizational Behavior and Human Decision Processes, 69(2),117-132.

Edmondson, A. C. (1999). Psychological safety and learning behavior in work teams. Administrative Science Quarterly, 44, 350-383.

Farmer, Steven M., Van Dyne, Linn., Kamdar, Dishan. (2015). The contextualized self: How team-member exchange leads to coworker identification and helping OCB. Journal of Applied Psychology, 100(2), 583-595.

Gersick, C. J. C. (1988). Time and Transition in Work Teams: Toward a New Model of Group Development. The Academy of Management Journal, 31(1), 9-41.

Ghitulescu, B. (2006). Job crafting and social embeddedness at work. Unpublished doctoral dissertation, University of Pittsburgh.

Hair, J. F., Black, W. C., Babin, B. J., Anderson, R. E., \& Tatham, R. L. (2006). Multivariate Data Analysis (6 ${ }^{\text {th }}$ ed.), New Jersey: Prentice Hall.

Higgins, E. T., Shah, J., \& Friedman, R. (1997). Emotional Responses to Goal Attainment: Strength of Regulatory Focus as Moderator. Journal of Personality and Social Psychology, 72(3), 515-525.

Hoegl, M., Parboteeah, K. P., \& Gemuenden, H. G. (2003). When teamwork really matters: task innovativeness as a moderator of the teamwork-performance relationship in software development projects. Journal of Engineering and Technology Management, 20, 281-302.

Homans, G. C. (1958). Social behavior as exchange. The American Journal of Sociology, 12(2), 597-606.

James, L. R., Demaree, R. G., \& Wolf, G. (1984). Estimating within-group interrater reliability with and without response bias. Journal of Applied Psychology, 69, 85-98.

Keller, P. A. (2006). Regulatory focus and efficacy of health messages. Journal of Consumer Research, 33, 109-114.

Leana, C., Appelbaum, E., \& Shevchuk, I. (2009). Work process and quality of care in early childhood education: The role of job crafting. Academy of Management Journal, 52, 1169-1192.

Levine, J. M., Higgins, E. T., \& Choi, H. S. (2000). Development of strategic norms in groups. Organizational Behavior and Human Decision Process, 82(1), 
88-101.

Liao, H., Liu, D., \& Loi, R. (2010). Looking at both sides of the social exchange coin: A social cognitive perspective on the joint effects of relationship quality and differentiation on creativity. Academy of Management Journal, 53(5), 1090-1109.

Liberman, N., Idson, L. C., \& Higgins, E. T. (2005). Predicting the intensity of losses vs. non-gains and non-losses vs. gains in judging fairness and value: A test of the loss aversion explanation. Journal of Experimental Social Psychology, 41(5), 527-534.

Lockwood, P., Jordan, C. H., \& Kunda, Z. (2002). Motivation by positive or negative role models: Regulatory focus determines who will best inspire us. Journal of Personality and Social Psychology, 83(4), 854-864.

McClelland, G. P., Leach, D. J., Clegg, C. W., \& McGowan, I. (2014). Collaborative crafting in call centre teams. Journal of Occupational and Organizational Psychology, 87, 464-486.

Niessen, C., Weseler, D., \& Kostova, P. (2016). When and why do individuals craft their jobs? The role of individual motivation and work characteristics for job crafting. Human Relations, 69(6), 1287-1313.

Podsakfoff, P.M., MacKenzie, S.B., Lee, J.Y.,\& Podsakoff, N.P., (2003). Common Method Biases in Behavioral Research: A Critical Review of the Literature and Recommended Remedies, Journal of Applied Psychology, 88(5), 879-903.

Postmes, T., Spears, R., \& Lea, M. (2000). The formation of group norms in computer-mediated communication. Human Communication Research, 26, 341-371.

Salas, E., Shuffler, M. L., Thayer, A. L., Bedwell, W. L., \& Lazzara, E. H. (2015). Understanding and improving teamwork in organizations: A scientifically based practical guide. Human Resource Management, 54, 599-622.

Seers, A. (1989). Team-member exchange quality: a new construct for role-making research. Organizational Behavior and Human Decision Processes, 43(1), 118-135.

Taggar, S., \& Ellis, R. (2007). The role of leaders in shaping formal team norms. The Leadership Quarterly, 18, 105-120.

Tims, M., \& Bakker, A. B. (2010). Job crafting: Towards a new model of individual job redesign. South African Journal of Industrial Psychology, 36, 1-9.

Tims, M., Bakker, A. B., \& Derks, D. (2012). Development and validation of the job crafting scale. Journal of Vocational Behavior, 80(1), 173-186.

Tims, M., Bakker, A. B., Derks, D., \& Van Rhenen, W. (2013). Job crafting at the team and individual level: Implications for work engagement and performance. Group \& Organization Management, 38(4), 427-454. 
Torrente, P., Salanova, M., Llorens, S., \& Schaufeli, W. B. (2012). Teams make it work: How team work engagement mediates between social resources and performance in teams. Psicothema, 24, 106-112.

Vaskova, R. (2007). Teamwork and high performance work organization. In European Foundation for the Improvement of Living and Working Conditions.

Weick, K. E. (1979). The social psychology of organizing (2 ${ }^{\text {nd }}$ ed.). Reading, MA: Addison-Wesley.

Wrzesniewski, A., \& Dutton, J. E. (2001). Crafting a job: Revisioning employees as active crafters of their work. Academy of Management Review, 26(2), 179-201.

Wrzesniewski, A., Berg, J. M., \& Dutton, J. E. (2010). Turn the job you have into the job you want. Harvard Business Review, 88(6), 114-117. 
Table 1

The mean, SD, and Pearson's Correlation Coefficients for study variables

\begin{tabular}{lllllll}
\hline & M & SD & $\mathbf{1}$ & $\mathbf{2}$ & $\mathbf{3}$ & $\mathbf{4}$ \\
\hline 1. TMX & 3.84 & 0.24 & & & & \\
2. team job crafting behaviors & 3.49 & 0.32 & $.551^{* *}$ & & & \\
3.promotion focus & 4.00 & 0.47 & $.220^{* *}$ & $.284^{* *}$ & & \\
4.prevention focus & 3.55 & 0.56 & .080 & $.109^{*}$ & $.229^{* *}$ & \\
5.indivisual job crafting & 3.57 & 0.50 & $.253^{* *}$ & $.370^{* *}$ & $.558^{* *}$ & $.286^{* *}$ \\
\hline
\end{tabular}

$N=364 ;{ }^{*} \rho<.05^{* * *} \rho<.01 \stackrel{* * * *}{\rho}<.001$

Table 2

The relationships among team-member exchange behaviors, individual and team job crafting behaviors

\begin{tabular}{|c|c|c|c|c|c|c|}
\hline \multirow[t]{2}{*}{ Model } & \multirow{2}{*}{$\begin{array}{l}\text { Individual } \\
\text { job crafting } \\
\text { Model } 1\end{array}$} & \multirow{2}{*}{\begin{tabular}{l}
\multicolumn{1}{c}{ Team } \\
Job crafting \\
Model 2
\end{tabular}} & \multicolumn{4}{|c|}{$\begin{array}{l}\text { Individual } \\
\text { job crafting }\end{array}$} \\
\hline & & & Model 3 & Model 4 & $95 \% \mathrm{CI}$ & \\
\hline Within level & & & & & $\begin{array}{l}\text { Lower } \\
\text { Limit }\end{array}$ & $\begin{array}{l}\text { Upper } \\
\text { Limit }\end{array}$ \\
\hline $\begin{array}{l}\text { High school and } \\
\text { below }\end{array}$ & $-.178^{*}$ & & -.124 & -.136 & -.301 & .029 \\
\hline Junior College & -.054 & & -.002 & -.009 & -.171 & .152 \\
\hline Undergraduate & -.036 & & -.039 & -.041 & -.147 & .064 \\
\hline Less than 1 year & $.161^{*}$ & & .123 & .127 & -.026 & .281 \\
\hline 1 years 3 years & .025 & & .002 & .005 & -.114 & .124 \\
\hline 3 years $\sim 5$ years & .015 & & .002 & .001 & -.185 & .187 \\
\hline 5 years 7 years & -.004 & & -.015 & -.014 & -.188 & .159 \\
\hline 7 years $\sim 10$ years & .143 & & .147 & .141 & -.049 & .332 \\
\hline$R^{2}$ & $.036^{*}$ & & .024 & .026 & & \\
\hline Between level & & & & & & \\
\hline TMX & $.485^{* * * *}$ & $.646^{* * * *}$ & & .162 & -.106 & .431 \\
\hline $\begin{array}{l}\text { Team job } \\
\text { crafting }\end{array}$ & & & $.536^{* * *}$ & $.468^{* * * *}$ & .278 & .658 \\
\hline$R^{2}$ & $.299^{*}$ & $.254^{* * * *}$ & $.562^{* * * *}$ & $.581^{* * * *}$ & & \\
\hline Indirect effect & & & & $.302^{* * * *}$ & .144 & .460 \\
\hline Total effect & & & & $.464^{* * * *}$ & .219 & .710 \\
\hline
\end{tabular}


Table 3

Moderated mediation of promotion regulatory focus

\begin{tabular}{|c|c|c|c|c|c|}
\hline \multirow[t]{4}{*}{ Model } & \multicolumn{5}{|c|}{ Individual job crafting } \\
\hline & \multirow[t]{3}{*}{$\beta$} & \multirow[t]{3}{*}{$(S E)$} & \multicolumn{2}{|c|}{$95 \% \mathrm{CI}$} & \multirow[t]{3}{*}{$R^{2}$} \\
\hline & & & Lower & Upper & \\
\hline & & & Limit & Limit & \\
\hline \multicolumn{6}{|l|}{ Within level } \\
\hline High school and below & -.027 & $(.08)$ & -.191 & .137 & \multirow[t]{9}{*}{$.298^{* *}$} \\
\hline Junior College & .020 & $(.07)$ & -.115 & .155 & \\
\hline Undergraduate & -.019 & $(.04)$ & -.103 & .065 & \\
\hline Less than 1 year & .121 & $(.08)$ & -.026 & .268 & \\
\hline 1 years 3 years & .022 & $(.06)$ & -.097 & .141 & \\
\hline 3 years $\sim 5$ years & -.026 & $(.08)$ & -.180 & .128 & \\
\hline 5 years 7 years & .041 & $(.08)$ & -.115 & .197 & \\
\hline 7 years 10 years & .130 & $(.09)$ & -.041 & .301 & \\
\hline \multirow{2}{*}{ Promotion focus } & $.496^{* * *}$ & $(.05)$ & .397 & .595 & \\
\hline & \multicolumn{5}{|c|}{ Team job crafting } \\
\hline \multicolumn{6}{|l|}{ Between level } \\
\hline \multirow[t]{2}{*}{ TMX } & $.646^{* * * * 4}$ & $(.13)$ & .384 & .907 & $.254^{* * *}$ \\
\hline & \multicolumn{5}{|c|}{ Individual job crafting } \\
\hline TMX & .041 & $(.12)$ & -.197 & .280 & $.384^{*}$ \\
\hline Individual job crafting & $.306^{* *}$ & $(.11)$ & .089 & .523 & \\
\hline Promotion focus & .091 & $(.11)$ & -.118 & .300 & \\
\hline $\begin{array}{l}\text { Team job crafting } \times \text { promotion } \\
\text { focus }\end{array}$ & .047 & $(.28)$ & -.505 & .598 & \\
\hline
\end{tabular}


Table 4

Moderated mediation of prevention regulatory focus

\begin{tabular}{|c|c|c|c|c|c|}
\hline \multirow[t]{4}{*}{ Model } & \multicolumn{5}{|c|}{ Individual job crafting } \\
\hline & \multirow[t]{3}{*}{$\beta$} & \multirow[t]{3}{*}{$(S E)$} & \multicolumn{2}{|c|}{$95 \% \mathrm{CI}$} & \multirow[t]{4}{*}{$R^{2}$} \\
\hline & & & Lower & Upper & \\
\hline & & & Limit & Limit & \\
\hline \multicolumn{5}{|l|}{ Within level } & \\
\hline High school and below & $-.212 *$ & $(.08)$ & -.375 & -.050 & \multirow[t]{10}{*}{$.092^{* * *}$} \\
\hline Junior College & -.065 & $(.09)$ & -.233 & .102 & \\
\hline Undergraduate & -.048 & $(.05)$ & -.148 & .052 & \\
\hline Less than 1 year & .074 & $(.08)$ & -.076 & .225 & \\
\hline 1 years 3 years & -.045 & $(.06)$ & -.163 & .073 & \\
\hline 3 years $\sim 5$ years & -.037 & $(.09)$ & -.216 & .142 & \\
\hline 5 years 7 years & -.047 & $(.08)$ & -.212 & .118 & \\
\hline 7 years 10 years & .072 & $(.09)$ & -.098 & .243 & \\
\hline \multirow[t]{2}{*}{ Prevention focus } & $.203^{* * *}$ & $(.05)$ & .105 & .301 & \\
\hline & \multicolumn{4}{|c|}{ Team job crafting } & \\
\hline \multicolumn{6}{|l|}{ Between level } \\
\hline TMX & $.646^{* * * *}$ & $(.13)$ & .384 & .907 & \multirow[t]{2}{*}{$.254^{* *}$} \\
\hline \multicolumn{5}{|l|}{ Between level } & \\
\hline TMX & $.438^{* * * *}$ & $(.09)$ & -.091 & .405 & \multirow[t]{10}{*}{$.674^{* *}$} \\
\hline Team job crafting & .157 & $(.13)$ & .261 & .616 & \\
\hline Prevention focus & .098 & $(.09)$ & -.085 & .281 & \\
\hline $\begin{array}{l}\text { Team job crafting } \times \\
\text { prevention focus }\end{array}$ & $.378^{+}$ & $(.21)$ & -.029 & .786 & \\
\hline \multicolumn{5}{|l|}{ Indirect effect } & \\
\hline Prevention focus-2SD & .133 & $(.09)$ & -.050 & .317 & \\
\hline Prevention focus $-1 \mathrm{SD}$ & $.208^{* *}$ & $(.07)$ & .067 & .350 & \\
\hline Prevention focus MED & $.283^{* * *}$ & $(.08)$ & .134 & .432 & \\
\hline Prevention focus $+1 \mathrm{SD}$ & $.358^{* * *}$ & $(.10)$ & .157 & .559 & \\
\hline Prevention focus $+2 S D$ & $.433^{* *}$ & $(.14)$ & .160 & .705 & \\
\hline
\end{tabular}


Table 5

high-prevention, high-promotion regulatory focus moderate the relationship between individual and team job crafting

\begin{tabular}{|c|c|c|}
\hline $\begin{array}{l}\text { Group } \\
\text { Model }\end{array}$ & $\begin{array}{l}\text { high-prevention } \\
\text { Individual job crafting } \\
\beta \quad(S E)\end{array}$ & $\begin{array}{l}\text { high-promotion } \\
\text { Individual job crafting } \\
\beta \quad(S E)\end{array}$ \\
\hline \multicolumn{3}{|l|}{ Between level } \\
\hline TMX & .004 & $.394^{*}$ \\
\hline Team job crafting & $.663^{* * *}$ & .068 \\
\hline$R^{2}$ & $.577^{* * * *}$ & .529 \\
\hline
\end{tabular}




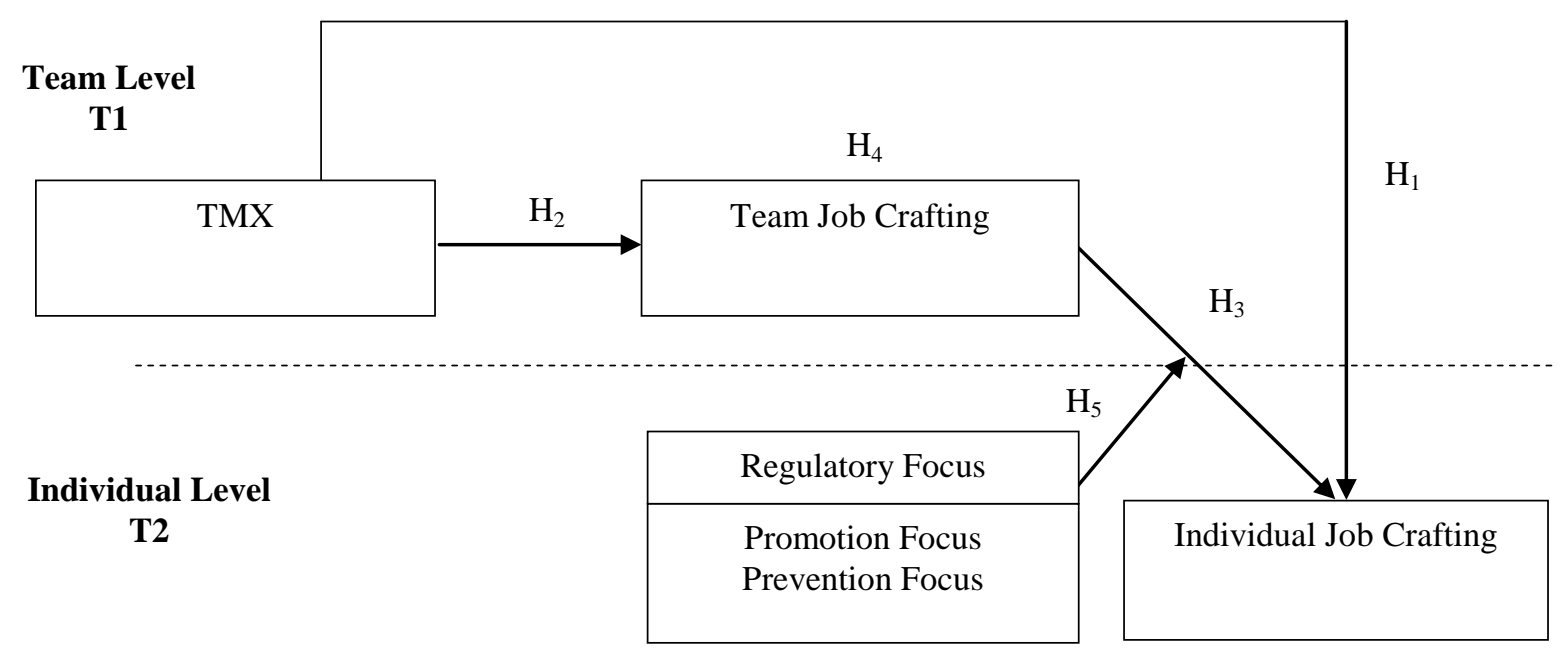

Figure 1

Research Structure

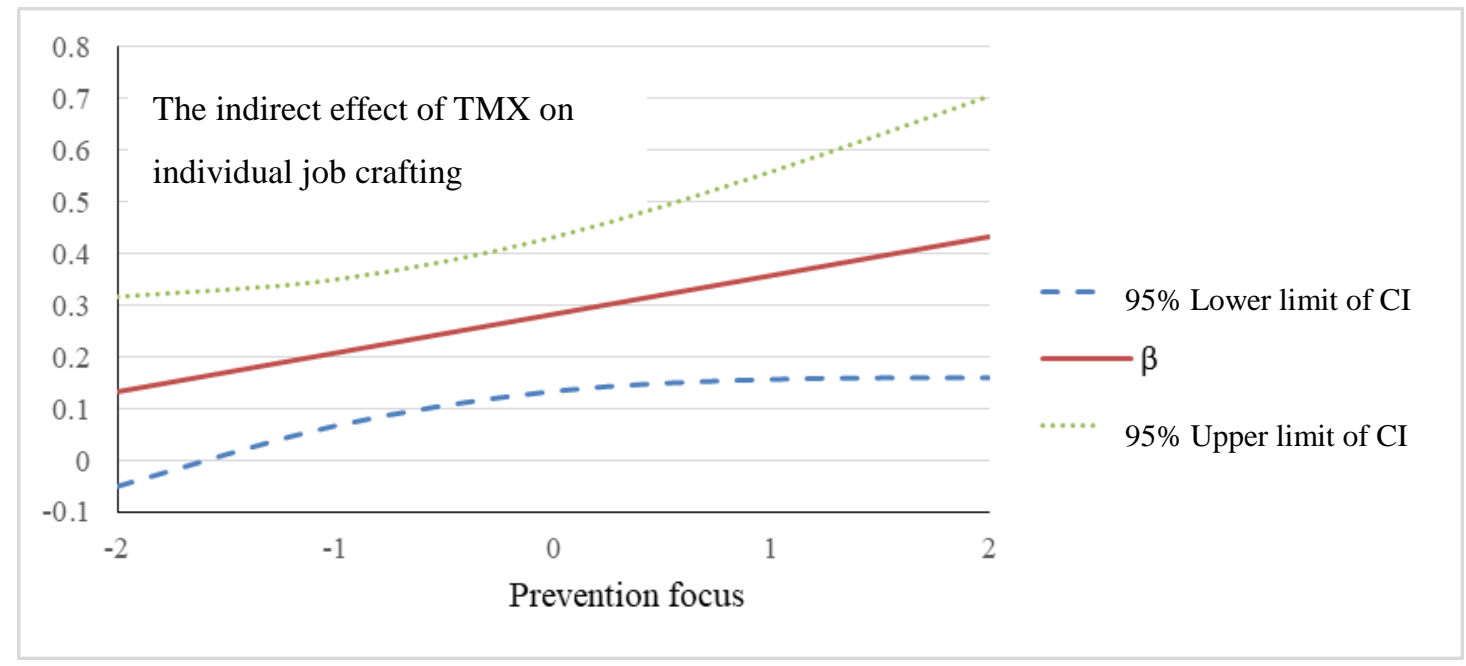

Figure 2

Moderating effect of prevention focus

$$
\frac{(\beta 1-\beta 2)}{\sqrt{(\operatorname{Se} \beta 1)^{2}+(\operatorname{Se} \beta 2)^{2}}}=\frac{(0.663-0.068)}{\sqrt{(0.123)^{2}+(0.177)^{2}}}=2.76
$$

Figure 3

The formula for $\beta$ coefficient calculation. 